\title{
Article
}

\section{Experiences of social work intervention among mothers with perinatal mental health needs}

Lever Taylor, Billie, Mosse, Liberty and Stanley, Nicky

Available at http://clok.uclan.ac.uk/29638/

Lever Taylor, Billie, Mosse, Liberty and Stanley, Nicky ORCID: 0000-0002-76441625 (2019) Experiences of social work intervention among mothers with perinatal mental health needs. Health \& Social Care in the Community, 27 (6). pp. 1586-1596. ISSN 0966-0410

It is advisable to refer to the publisher's version if you intend to cite from the work. http://dx.doi.org/10.1111/hsc.12832

For more information about UCLan's research in this area go to http://www.uclan.ac.uk/researchgroups/ and search for <name of research Group>.

For information about Research generally at UCLan please go to http://www.uclan.ac.uk/research/

All outputs in CLoK are protected by Intellectual Property Rights law, including Copyright law. Copyright, IPR and Moral Rights for the works on this site are retained by the individual authors and/or other copyright owners. Terms and conditions for use of this material are defined in the policies page.

\section{CLoK}

Central Lancashire online Knowledge www.clok.uclan.ac.uk

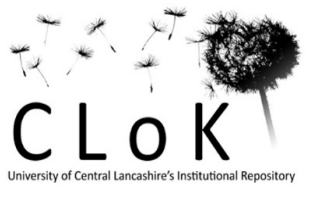




\section{Health and Social Care in the community}

\section{Experiences of Social Work Intervention among Mothers with Perinatal Mental Health Needs}

\begin{tabular}{|r|l|}
\hline Journal: & Health \& Social Care in the Community \\
\hline Manuscript ID & HSCC-OA-19-0196.R2 \\
\hline Manuscript Type: & Original Article \\
\hline Keywords: & $\begin{array}{l}\text { perinatal mental health, Social Work, Child Protection, mothers' } \\
\text { perspectives, Qualitative Research }\end{array}$ \\
\hline
\end{tabular}

\section{SCHOLARONE \\ Manuscripts}


Title: Experiences of Social Work Intervention among Mothers with Perinatal Mental Health Needs

\begin{abstract}
Perinatal mental health difficulties are prevalent among women, and the vulnerability of young infants makes this a time when families experiencing multiple adversities may be particularly likely to attract state intervention. However, very little is known about how mothers experience social work intervention during the perinatal period. The current study explored experiences of social work intervention among women with perinatal mental health difficulties. Qualitative semi-structured interviews were carried out with 18 women with 6-9 month old babies, who had been treated in England for a perinatal mental health difficulty and also had social services intervention. Interviews were analysed using thematic analysis. Findings suggested that mothers had a predominantly negative view of children's social services, especially when social workers had significant child protection concerns. The fear of being judged an unfit mother and having their babies taken away overshadowed their encounters. Mothers felt that social workers would not accept they could be good mothers in spite of their difficulties and set them up to fail. Some felt that social workers focused exclusively on the risks to the baby and did not acknowledge the mother's own needs or understand perinatal mental health. In some cases, social work intervention was described as intensifying pressure on mothers' mental health, leading to escalating difficulties and increased likelihood of care proceedings. At the same time, our study also included examples of mothers forming positive relationships with social workers, and of 'turning points' where initially negative interactions stabilised and child protection concerns lessened. Women's accounts highlighted the importance of feeling 'known' by social workers who understood and respected them. The findings also suggested there may be value in improving collaboration between social workers and mental health professionals to create more space for representation of women's needs as well as those of their babies.
\end{abstract}




\section{What is known about this topic}

- Many women experience perinatal mental health difficulties.

- They may be particularly likely to attract social services intervention due to the vulnerability of their infants.

- Little is known about how women experience social services intervention in this context.

\section{What this paper adds}

- Mothers had a predominantly negative view of social work intervention, saying social workers misjudged them, lacked an understanding of perinatal mental health and set them up to fail.

- Social work was more likely to be experienced positively when mothers felt known, listened to and understood.

- Improved collaboration between social workers and mental health professionals could help ensure mothers' and babies' needs are met.

Key words: perinatal mental health; social work; child protection; qualitative research; mothers' perspectives 


\section{Introduction}

There has been increasing interest in the experiences of mothers who encounter child protection services when their children are infants. The vulnerability of the young infant makes the perinatal period, which spans from pregnancy to one-year post-birth, a time when families experiencing multiple adversities may be particularly likely to attract state intervention: Broadhurst et al (2018) note that infants represented 27\% of children in care proceedings in England between 2007/08 and 2016/17 and their analysis of CAFCASS data showed steep increases in the numbers of new-borns subject to care proceedings over this period. Alongside domestic violence and substance misuse, parental mental health problems have long been implicated in the risks to children's safety and welfare (Cleaver et al 1999; Falkov 1998; Park et al 2006; Royal College of Psychiatrists 2011; Westad and McConnell 2011). Broadhurst et al's (2017) study of mothers involved in recurrent care proceedings found that over half had mental health issues with rates of domestic violence and substance misuse at similar levels. These mothers had high levels of exposure to abuse and neglect in childhood with about 40 percent having themselves experienced out-of-home care or, in UK terminology, been 'looked after' by local authorities. Research on adverse childhood experiences (Felitti et al, 1998) has highlighted the role of childhood trauma in adult mental health disorders which, in turn, have implications for parenting.

Perinatal mental health problems affect 10-20\% of mothers in the UK (Bauer et al., 2014) and pose risks for mothers themselves as well as for infants. Suicide was the leading cause of maternal deaths occurring within a year after pregnancy recorded by the Confidential Enquiries into Maternal Deaths and Morbidity 2014-16 report (Knight et al 2018), with some suicides following a major loss such as having a child removed into care. While the diagnosis of a perinatal mental health problem can heighten professionals' awareness of risks for both mothers and infants, it should be acknowledged that the majority of perinatal mental health disorders are transient: women often make a good recovery and associated risks to their children lessen (Howard et al., 2014; Stein et al., 2014). The decisions and interventions of 
child protection social workers, whose primary responsibility is for the safety and wellbeing of children, may however have long-term consequences. Surprisingly, however, there has been little exploration of how perinatal mental health difficulties may contribute to safeguarding concerns or how women experience social work intervention in this context.

A few qualitative studies have elicited perceptions of social services from mothers with mental health problems beyond the perinatal period. Sheppard and Kelly's (2001) early study of depressed mothers with children subject to child protection investigations found that women expressed feelings of lack of control, entrapment and blame and feared losing custody of their children. [Author's] (2003) study of women with a diagnosis of mental illness and recent experience of a child protection case conference noted that their relationships with child care social workers were frequently adversarial and characterised by an absence of trust and withholding of information by both parties. Women were more likely to confide in mental health professionals who were experienced as non-judgmental and 'there for them'.

Neither of the studies cited above focused specifically on the perinatal period. Yet this is a unique period of transition for women and their families, connected with challenges and risks that are distinct from other times in their lives (Brockington, 2004). The current study therefore concentrates attention on women with perinatal psychiatric difficulties, using qualitative interviews to explore mothers' experiences of social work intervention.

\section{Methods}

This research was part of a wider research programme examining experiences of perinatal mental health care in England that included qualitative, semi-structured interviews with women treated for perinatal mental health difficulties. The qualitative methodology enabled participants to voice their views in their own words and allowed for in-depth exploration of an area where research evidence is limited. The current study focused on analysing women's experiences of social services intervention. National Health Service (NHS) ethics approval was obtained (reference: 13/LO/1855). 


\section{Data collection}

Interviews lasting roughly an hour took place from June 2015-March 2017 in women's homes, unless participants preferred an alternative location (e.g. a café or NHS service). A semi-structured topic guide was developed by the study team, which included qualified mental health and social work clinicians and researchers. Given the novelty of the topic area and exploratory nature of the study, interview questions were purposely broad and open.

The topic guide was reviewed by a service user advisory panel and amended following their feedback. Further minor amendments were completed subsequent to five pilot interviews. As this study was part of wider research, interviews asked women about their experiences of all services/professionals they had contact with in relation to their perinatal mental health. For those who had contact with social services, the topic guide included the following questions: Can you tell me a bit about what happened? What was your experience of this? How did you feel about the involvement of these services? How did you experience the professionals involved? The current study focused on analysing responses to these questions. Brief sociodemographic and diagnostic information was also obtained from women.

\section{Participants}

Altogether, 52 women were recruited from eleven NHS healthcare providers across different areas of England, which varied in their urbanicity. Purposive sampling was used to ensure diversity of diagnosis and socio-demographic background. Inclusion criteria required that women were $\geq 16$ years; had a 6-9-month-old baby; and had accessed NHS treatment for a perinatal mental health difficulty (during/after their most recent pregnancy). Due to lack of resources for accessing interpreters, non-English speakers were excluded. Eligible women were initially identified and approached by mental health clinicians. Participation was voluntary and women were informed that their care would not be affected if they declined to take part. Researchers obtained consent from women for their interviews being audiorecorded, transcribed and written up for publication (after anonymisation). 
Women did not have to have had social services involvement to take part in the wider study. However, the current study included 18 women from the wider sample, who all described substantial social services intervention (either after self-referring to social services or being referred by professionals). Social services intervention was defined to mean women had met in person with qualified social workers who had child protection concerns.

Seventeen of the eighteen interviews were undertaken by the first author, who is a mother, clinical psychologist and researcher. The remaining interview was conducted by the third author, who is a mother, qualified social worker and researcher.

\section{Analysis}

The second author, a researcher with lived experience of using perinatal mental health services, analysed data using NVivo software. Braun and Clarke's (2006) six phases of thematic analysis were followed, informed by Maguire and Delahunt's (2017) guidelines. In line with these phases: i) transcripts were read and re-read and initial observations were noted; ii) relevant segments of text were systematically broken down into small chunks of meaning, assigned labels and inductively developed into codes; iii) codes were then gathered into themes to create a provisional coding frame (e.g. the text included in the 'Results' section: "she told me she had gone through my social services files from when I was a teenager..." was initially coded as 'seen in light of past', while the text: "They don't want to give you a fresh start and sometimes look at the now rather than the past." was coded as 'overlooking change/the present'. These were then ultimately combined with other codes into the sub-theme 'denied a fresh start'); iv) The third author (who read half the transcripts) then met with the second author to discuss provisional themes and the coding frame was updated; v) The second and third authors then met three times with the first author (who read all transcripts) and a comprehensive thematic framework was finalised collaboratively; vi) Findings were then written up. 


\section{Results}

\section{Participant characteristics}

Table 1 shows demographic and clinical characteristics of the 18 participating mothers. They are divided into two groups: column B shows figures for 'high social services involvement' (HSSI) mothers - that is those where it was clear that children's social services had considerable concerns (e.g. there was a child protection plan in place; the mother was undergoing a parenting assessment; or the mother did not have custody of her baby). Column C shows characteristics of lesser social services involvement (LSSI) mothers - i.e. those who had met with social workers about child protection concerns, but where these concerns were not significant enough to merit a child protection plan, parenting assessment, loss of custody or similar. Column A shows figures for the wider sample of 52 mothers for comparison.

Although the small numbers make the findings tentative, it can be seen that the $11 \mathrm{HSSI}$ mothers had conspicuously different clinical and demographic profiles to mothers in the wider sample: the majority of HSSI mothers were not living with a partner, very few owned or privately rented their homes and a large proportion reported a diagnosis of personality disorder. It is not known, however, whether such factors influenced referral to social services.

Five of these 11 mothers did not have custody of their babies at the time of interview. None of them was living with a partner, four were $\leq 25$ and four had a personality disorder diagnosis (the other had a diagnosis of depression). In three cases, this was the mother's first child, while two had other children who had also been taken into care.

The 11 HSSI mothers described experiences of homelessness, deprivation, domestic violence, sexual abuse, alcohol and drug misuse, relationship breakdown, and social services involvement themselves as children. Several disclosed long histories of mental health problems, self-harm and suicide attempts. Over half had been referred to a parent-infant team for help with difficulties bonding with their babies. 
Overall, this group of mothers appeared distinct not only from the wider sample, but also from LSSI mothers. LSSI mothers seemed particularly likely to report a diagnosis of bipolar disorder, psychosis or schizophrenia and to have accessed acute general psychiatric services, suggesting that the severity of their mental health difficulties and/or type of service accessed may sometimes have prompted social services involvement. Other than this, LSSI mothers did not differ as conspicuously from the wider sample in their demographic or clinical profiles.

\section{Key themes}

The key themes and sub-themes derived from the thematic analysis are shown in Table 2.

Overall, women often felt that social workers did not accept they could be good mothers and set them up to fail. The fear of losing their baby overshadowed their encounters and ran through all the themes. Mothers with more positive views were mostly those where social services had less significant concerns (i.e. LSSI mothers). Even so, there were instances where HSSI mothers formed good relationships with individual social workers and examples of 'turning points', where interactions with social workers shifted towards a more positive position. These themes are explored below.

\section{Labelled as 'bad mothers'}

Although participating mothers often found pregnancy and having a baby challenging, many also saw the perinatal period as offering an opportunity for growth and development. However, several women felt that social workers did not share this view, seeing them as inevitably unfit to parent because of their past difficulties and current mental health problems. Fears of losing custody of their babies ran high.

\section{Denied a fresh start}

Women living in challenging circumstances, in particular many of the HSSI mothers, often said they hoped that becoming a mother would offer them a fresh start: 
"I had gone from not being allowed to be responsible for myself at times, to suddenly actually responsible for somebody else...A lot of people said it probably saved my life, because I did just turn my life around".

Mother-13 [HSSI]

Women wanted to mitigate the effects of their difficulties on their babies and to be the best parents they could be. Some said they had approached social services themselves or sought other professional help early on in their pregnancies, in a bid to prepare themselves and give their baby the best start in life:

"[I said] if I was to ever bring another child into the world I would do my absolute best to make sure that that doesn't happen [that I become unable to cope]...I needed to put myself in a situation where I knew that I could ask for help and at least have some sort of coping strategies."

Mother-18 [HSSI]

A few mothers who approached social services early on were told they could not be seen until they were 4-5 months pregnant, leaving them without early input. Once social workers did become involved, several women expressed dismay that they did not share the view that the perinatal period could be a new beginning. From mothers' perspectives, which is our focus here, there was an over-reliance on negative accounts from their pasts:

"Basically she told me that she had gone through my social services files from when I was a teenager...I ask these people, 'Where did you get your information from?' 'Oh well, it's in your social services notes.'... There was other misleading information in there as well."

Mother-11 [HSSI]

It should be noted that some women with a history of acute mental health or substance misuse difficulties, even previous custody loss, had only brief encounters with social services (i.e. some LSSI women), suggesting that past child protection and/or mental health concerns did not in fact inevitably result in ongoing serious child protection concerns. However, HSSI women, who were hoping for a fresh start, experienced frustration when social workers seemed reluctant to accept they had made changes in their lives, instead seeing them as inevitably presenting a risk:

"[Social services] like to look at your file from the past and make a judgement from that... They don't want to give you a fresh start and sometimes look at the now rather than the past." 
Mother-12 [HSSI]

\section{Misunderstanding mental health}

Although several mothers felt judged by their pasts, they did acknowledge that social workers were generally also acting on things said or done in the present. These were often very serious behaviours, such as neglecting, abusing or threatening to harm their babies. In these cases, however, mothers usually considered they had been misunderstood or misrepresented. It was common for women to report that social services did not understand mental health difficulties or their manifestations, leading them to overreact:

[Social services] paired me up with someone who literally had no history of mental health...Like a social worker that clearly, you know, did not even know how to address it."

Mother-13 [HSSI]

Some mothers, particularly those with personality disorder diagnoses, felt that once social workers became aware of their mental health difficulties, they were stigmatised as unfit mothers:

"The first social worker used to look at me like I was an alien...I don't know if they have a full understanding...that even if someone's got a mental illness they can still be a good parent."

Mother-15 [HSSI]

This was sometimes contrasted with mental health professionals, who some mothers said understood and supported them better, and were more likely to believe their mental health could improve:

"They write on a board, strengths, weaknesses, dangers, blah blah blah. Any time [my perinatal psychologist] came out with a positive thing [the social worker] was so reluctant to write it on the board."

Mother-18 [HSSI]

There were exceptions to this, however, where mothers said social workers had been reassuring and understanding about their mental health difficulties. This was much more likely in cases where social workers had less significant child protection concerns, i.e. for LSSI women, most of whom were either positive or neutral about social workers: 
"Having a big talk to [social services]... helped me to rationalise and to understand, okay, why I felt the way I did, and to get the medication started... They were very calm and, you know, non-judgemental...They could see that I wasn't somebody who was, you know, actually going to damage [my baby]."

Mother-2 [LSSI]

In a few cases, HSSI mothers also spoke positively about individual social workers. This generally occurred where they felt social workers did not judge them, but viewed them as normal people doing their best:

"We used to sit on the couch and take our shoes off and just chill. [The social worker] ...was like a friend, you know?...She didn't feel threatened for her life. She stayed with me and chilled."

Mother-4 [HSSI]

Frequently though, HSSI mothers felt harassed, scrutinised and oppressed by social workers.

Some said this significantly worsened their mental health, creating a downward spiral:

"I'm stuffing myself with pills to help with anxiety...If I was feeling suicidal at the beginning, you know, when I left the hospital, now I feel four times more suicidal because of what [social services] are doing."

Mother-1 [HSSI]

\section{Set up to fail}

Connected to this, some mothers expressed a belief that social workers set them up to fail rather than helping them succeed. This could occur when mothers felt trapped in 'double bind' situations; believed their own needs were not addressed; felt social workers placed additional strain on them and their families; and when they felt powerless. These sub-themes are discussed below.

\section{Double bind}

A few mothers described feeling trapped in 'double bind' situations. If they were open about their mental health difficulties, they felt they were viewed as a risk to their babies. But if they were unforthcoming, they could be classified as failing to engage and therefore also a risk. If they became upset or challenged social workers, they felt they were accused of being volatile and aggressive. But if they did not seem upset enough, they feared social workers would say 
they did not care about their babies or were unresponsive. When mothers felt trapped, the situation could rapidly escalate:

"[The social worker] was saying...'nothing's changing, and we have to think about taking the kids'. And so I said to her it would be over my dead body, 'If you think you're taking my kids I'll kill myself and them'. And she was like, 'Well, if you're saying something like that, we just may as well just take them'."

Mother-6 [HSSI]

Mothers struggled to communicate a need for help without appearing to be a risk, especially as some were trying to refrain from behaviours they previously used when distressed (e.g. drug misuse or suicide attempts).

"I just thought that because [my baby] was on the care plan that if I admitted that I didn't love him... he was going to get taken away from me. And I didn't want that because I've wanted a baby for so long."

Mother-11 [HSSI]

\section{Not addressing mothers' own support needs}

Some mothers felt that social workers focused solely on the risk to the baby, ignoring mothers' needs. They considered that social workers failed to appreciate that their own needs were inextricably connected to those of their babies and that meeting a mother's need for support (e.g. with parenting, mental health or wider family relationships) might be the best way to protect her baby, especially as several said they had not been parented well themselves and wanted guidance:

"They're only here for [the baby], you know... If you want [my baby] to do well, we need to be well as well. Well, I need to be well."

Mother-13 [HSSI]

A few mothers felt that, rather than addressing their needs, social services and those connected to them undermined them, making them more likely to 'fail'. For example, one mother who was placed with her baby in a foster placement felt the foster carer took over, pushing her out and making her feel increasingly hopeless:

"[The foster carer] would muddle in and take over feeding, bottle feeding, bathing sometimes or washing [my baby], changing her...Whereas I was like, no I want to be doing [that]...But I knew I couldn't be argumentative... She was trying to work her way, in my eyes, to getting my daughter taken off me."

Mother-12 [HSSI] 
"[Social services] didn't see how difficult it was...They're sort of saying to you, 'Well you can still see him.' Yes, but I can't see him unless I've got someone watching my every move with him... How can you expect me to learn to be a mum when I can't even wake up next to my baby?"

Mother-13 [HSSI]

\section{Increasing the strain on families}

Although some LSSI mothers viewed social services as trying to unite and support families "working with us to get us to where we need to be" (Mother-5, LSSI), most HSSI mothers believed they placed additional strain on women and their families.

Some women were engaged in custody disputes and believed social services, along with wider court processes and legal procedures, tended to pit family members against each other. Some mothers felt they were placed under greater scrutiny than fathers:

"Everything you do is under a microscope, whereas [my ex-partner] hasn't had to prove himself."

Mother-13 [HSSI]

In a few cases, mothers feared social services were deliberately seeking to paint a negative picture of them to justify separating their babies from them: "they'll twist the truth slightly to make a case against you (Mother-12, HSSI).

Mothers who had their babies removed found the experience acutely distressing. They often felt they had not been supported to keep their babies and were then abandoned, with little support to help them cope with the loss or regain custody. They were left dealing with intense grief, wanting to be reunited with their babies, and struggling to come to terms with their experiences:

"I've been through two vagina removals (babies removed shortly after birth) before [this baby was taken away]. I never dealt with the loss of those two babies because I was intoxicated. I'm dealing with it now. I'm dealing with all of it now...There's no help out there for people like me." 
Mother-4 [HSSI]

\section{Powerlessness}

Many mothers felt powerless in relation to social services. Decisions about their babies' futures felt as though they were out of their control as mothers got "deeper and deeper in the **** with social services" (Mother-1, HSSI). Mothers believed social workers did not listen to them or take their perspectives on board:

"She just spoke to my mum and then wrote a big report about how I can't look after [my baby]... The report talks about how my health was, but she didn't even talk to me."

Mother-10 [HSSI]

Procedures seemed opaque, making decisions feel unexpected and leaving mothers unsure how to respond:

"I was told by the police, you know, 'We have no concerns for your parenting...Our concerns are just mainly for you'... Like next day, I've got social standing on my doorstep telling me that [my baby's]... got to stay at [his dad]'s for a couple of days...A couple of days turned into a couple of weeks, turned into a couple of months."

Mother-13 [HSSI]

By contrast, 'straight talking' and being given a sense of agency was valued:

"[My social worker] says it as it is. She says to me, 'If you work with me I will work with you back. I will tell you how it is and I will get you where you want to get'. And yes, now she's a godsend."

Mother-11 [HSSI]

\section{Turning points}

Despite women's fears they were being set up to fail, six HSSI mothers retained custody of their babies when interviewed. In some cases, there appeared to have been 'turning points' where initially negative encounters with social workers stabilised, child protection concerns reduced, and mothers came to feel better supported. Sometimes, changes were attributed to external factors (e.g. women meeting a new partner), but in three cases in particular, there were also indications of shifts in women's interactions with social services. These are described below.

\section{A fresh perspective: someone 'on their side'}


"He knows me. He knows exactly what I've been through...And he dismissed a lot of it. He said, '...that's not relevant... This is actually how far [she] has come. This is where she is today."

\section{A change in perspective: feeling 'known'}

Connected to this, when social workers saw mothers as a 'known quantity', rather than as unpredictable and volatile (and vice-versa), the relationship appeared smoother. One mother described how she and social workers learnt to know and understand each other better. She attributed this to shifts in communication styles on both sides that resulted in social workers seeing her as a mother in need of support, rather than a risk:

"I didn't feel like anybody was listening to me... when they finally did listen everybody just kind of clicked...

...I was like, 'Look, I've been telling you for ages that I haven't been parented. I'm the one who needs the help, not the kids.'...And then after that everybody calmed down and started talking...It took a long time...I think I lost my temper, and then I kind of calmed down and thought, actually shouting's never got you anywhere really, so say it again, but say it with a bit more, like...feeling and calm."

Mother-6 [HSSI] 
From this point onwards, she had become more able to utilise social work support and communicate how she was feeling: "If I don't answer the phone, send me a text, and if I don't respond, I'm not in a good place". Consistency was key too, as she disliked having to "rebuild up everything” with new people.

\section{Discussion}

This study is unique in exploring experiences of social work intervention among mothers with perinatal mental health difficulties. Despite their vulnerability to child protection interventions (Broadhurst et al., 2017 \& 2018), there has been limited focus on their experiences. Although our study was relatively small, participating mothers had a range of diagnoses and socio-demographic backgrounds. Several had lost custody of their babies and many, particularly those where there were significant child protection concerns, described growing up and/or living in challenging social circumstances. A large proportion of these mothers also had personality disorder diagnoses and it has been argued that conceptualising difficulties in this way may engender low expectations among practitioners of parenting capacity and ability to change (Authors, 1999; Ramon et al., 2001).

Overall, as in research outside the perinatal period (Authors, 2003), most mothers had a negative view of social workers, especially when their intervention resulted in significant concerns. Fear that they would lose their babies loomed large, running through all the themes identified. Mothers said social workers did not accept them as good mothers and set them up to fail. Women struggled to communicate their needs whilst presenting as competent mothers. They felt social workers lacked understanding of perinatal mental health and focused exclusively on the risks to the baby, rather than acknowledging the needs of the mother or recognising that addressing her needs might be the best way to reduce the risk to her baby.

Women found that social workers' communication often lacked clarity and, in common with Honey et al's (2018) study, procedures and decisions were described as opaque, making mothers feel powerless. Most worryingly, there were indications that social work intervention 
could intensify pressure on mothers' mental health leading to escalating difficulties and increased likelihood of care proceedings. Other research (Cox et al, 2017; Schofield et al, 2011) has highlighted how little social work support is available to mothers following loss of custody and the long-term consequences of such neglect can include repeated care proceedings (Broadhurst \& Mason 2017). New UK services such as PAUSE (McCracken et al 2017), MPower and Positive Choices (Cox et al, 2017) aim to halt the cycle of recurrent care proceedings but the need for proceedings could perhaps be reduced by strengthening social work intervention for mothers with perinatal mental health problems.

While some tension in women's relationships with social workers may be inevitable given the threat of custody loss, our study also included examples of mothers forming positive relationships with social workers, and of 'turning points' where initially negative interactions stabilised. While we cannot be sure of the direction of causality, women's accounts suggested that when they felt 'known', listened to and understood by social workers, this could help strengthen relationships and lessen child protection concerns. Feeling recognised, acknowledged and contained is considered vital if parents are to be able to hold their children 'in mind' (Howe, 2010), suggesting a need for social workers to invest time in getting to know mothers, understanding their needs, and being transparent about concerns and requirements for change (Turney, 2012).

Qualitative reviews (Doman et al 2013; Megnin-Viggars et al 2015) have argued for improved collaboration between professionals working with this group of mothers and more joint work between social workers and mental health professionals could be valuable especially since, like Authors (2003), our findings suggest that mothers may find it easier to trust mental health professionals. Close working between mental health and social care professionals could create more space for representation of women's needs as well as those of their babies, recognising how addressing a mother's own needs may in itself help address the child's needs in the longer-term (Authors, 2003). Davidson et al (2012) describe a successful 
Northern Ireland initiative which involved Champions in both mental health and child protection services promoting improved communication and joint work between practitioners.

While this study addressed a research gap, it also had limitations. Firstly, as the study was part of a wider research programme, only parts of each interview focused on experiences of social services. This limited the time that could be spent on this topic. Secondly, participating mothers had all accessed mental health services, and may therefore have differed from mothers without such support. Thirdly, while the ethnicity of our sub-sample of mothers with social work involvement may reflect wider patterns of social services' engagement with minority families (see Bywaters et al 2017), future research would benefit from including more women from minority backgrounds (e.g. Asian) as well as non-English speakers. This could help ensure that more diverse voices are heard and any issues unique to these groups of women are explored. Finally, future research may benefit from exploring the perspectives of social workers themselves.

\section{Conclusion}

Social workers often work in highly pressurised environments and are required to prioritise the safety of vulnerable infants. These conditions may make it challenging for them to recognise and respond appropriately to the needs of mothers with perinatal mental health difficulties. A well-developed understanding of perinatal mental health together with clear communication which conveys respect and regard for mothers appears helpful, and increased collaboration or joint work with mental health practitioners might allow for both mothers' and infants' needs to be acknowledged. Ensuring that staff with perinatal mental health expertise can represent mothers' perspectives and prospects for recovery is vital when the consequences of social work involvement may be profound and enduring for both mother and infant. Policy and practice development in respect of this has been piecemeal in England and Wales and has failed to build consistently on earlier guidance produced by the Social Care Institute for Excellence (SCIE, 2009) and the Royal College of Psychiatrists (2011). Both sets of guidance might be strengthened by co-ordinated updating. While the perinatal period can 
be conceptualised as a period of vulnerability for mothers and their babies, it is also a time when expectations for the future and potential for change can be high. Social workers need to identify means by which they can harness these positive aspirations to ensure the wellbeing and safety of mothers and infants. 


\section{References}

Authors (1999)

Authors (2003)

Bauer, A., Parsonage, M., Knapp, M., Lemmi, V., \& Bayo, A. (2014). The costs of perinatal mental health problems. Centre for Mental Health. Retrieved from http://eprints.lse.ac.uk/59885/.

Braun, V., \& Clarke, V. (2006). Using thematic analysis in psychology. Qualitative Research in Psychology, 3, 77-101. https://doi.org/10.1191/1478088706qp063oa.

Broadhurst, K., Alrouh, B., Mason, C., Ward, H., Holmes, L., Ryan, M., \& Bowyer, S. (2018). Born into Care: newborn babies subject to care proceedings in England. The Nuffield Family Justice Observatory: Nuffield Foundation, London. Retrieved from https://www.nuffieldfjo.org.uk/app/nuffield/filesmodule/local/documents/Born\%20into\%20Care_Final\%20Report_10\%200ct\%202018.pdf

Broadhurst, K. \& Mason, C. (2017). Birth Parents and the Collateral Consequences of Courtordered Child Removal: Towards a Comprehensive Framework, International Journal of Law, Policy and the Family, 31, 41-59. https://doi.org/10.1093/lawfam/ebw013.

Broadhurst, K., Mason, C., Bedston, S., Alrouh, B., Morriss, L., McQuarrie, T.,...Kershaw, S. (2017). Vulnerable Birth Mothers and Recurrent Care Proceedings: Final Main Report.

Lancaster: Lancaster University. Retrieved from https://www.nuffieldfoundation.org/sites/default/files/files/rc-final-summary-report-v1_6.pdf.

Brockington, I. (2004). Postpartum psychiatric disorders, The Lancet, 363(9405), 303-310. https://doi.org/10.1016/S0140-6736(03)15390-1.

Bywaters, P., Kwhali1, J., Brady, G., Sparks, T. \& Bos, E. (2017) Out of Sight, Out of Mind: Ethnic Inequalities in Child Protection and Out-of-Home Care Intervention Rates. British Journal of Social Work, 4(7), 1884-1902. https://doi.org/10.1093/bjsw/bcw165.

Cleaver, H., Unell, I., \& Aldgate, J. (1999). Children's needs - parenting capacity: the impact of parental mental illness, problem alcohol and drug use and domestic violence on children's development. The Stationery Office: London.

Cox, P., Barratt, C., Blumenfeld, F., Rahemtulla, Z., Taggart, D. \& Turton, J. (2017). Reducing recurrent care proceedings: initial evidence from new interventions, Journal of Social Welfare and Family Law, 39, 332-349. https://doi.org/10.1080/09649069.2017.1345083. 
Davidson, G., Duffy, J., Barry, L., Curry, P., Darragh, E., \& Lees, J. (2012). Championing the interface between mental health and child protection: evaluation of a service initiative to improve joint working in Northern Ireland. Child Abuse Review, 21, 157-172. https://doi.org/10.1002/car.1164.

Dolman, C., Jones, I., \& Howard, L. M. (2013). Pre-conception to parenting: a systematic review and meta-synthesis of the qualitative literature on motherhood for women with severe mental illness. Archives of women's mental health, 16:173-96. doi:10.1007/s00737-013-0336-0.

Falkov A (ed.) (1998). Crossing Bridges: Training resources for working with mentally ill parents and their children - Reader for managers, practitioners and trainers. Pavilion Publishing: Brighton.

Felitti, V.J., Anda, R.F., Nordenberg, D., Williamson, D.F., Spitz, A.M., Edwards, V., \& Marks, J.S. (1998). Relationship of childhood abuse and household dysfunction to many of the leading causes of death in adults: The adverse childhood experiences (ACE) study. American Journal of Preventive Medicine, 14, 245-258. http://dx.doi.org/10.1016/S0749-3797(98)00017-8.

Honey, A., Mayes, R. \& Miceli, M (2018) Mothering after child removal: Living under the rule of Greek gods. Child and Family Social Work, 23, 417-426. https://doi.org/10.1111/cfs.12432.

Howard, L.M., Molyneaux, C-L.D., Rochat, T., Stein, A., \& Milgrom, J. (2014). Non-psychotic mental disorders in the perinatal period. The Lancet, Nov 15; 384(9956): 1775-1788. doi:10.1016/S0140-6736(14)61276-9.

Howe, D. (2010). The safety of children and the parent-worker relationship in cases of child abuse and neglect. Child Abuse Review, 19, 330-341. https://doi.org/10.1002/car.1136.

Knight M., Bunch, K., Tuffnell, D., Jayakody, H., Shakespeare, J., Kotnis, R.,...Kurinczuk, J.J. (Eds.) (2018) Saving Lives, Improving Mothers' Care: Lessons learned to inform maternity care from the UK and Ireland Confidential Enquiries into Maternal Deaths and Morbidity 2014-16. Oxford: MBRRACE-UK.

Maguire, M. \& Delahunt, B. (2017). Doing a thematic analysis: A practical, step-by-step guide for learning and teaching scholars. AISHE-J, 3, 3351-33514. Retrieved from http://ojs.aishe.org/index.php/aishe-j/article/view/335.

McCracken, K., Priest, S., FitzSimons, A., Bracewell, K., Torchia, K., Parry, W., \& Stanley, N. (2017). Evaluation of Pause: Research report. Tech. rep. Retrieved from: https://dera.ioe.ac.uk/29588/1/Evaluation_of_Pause.pdf 
Megnin-Viggars, O., Symington, I., Howard, L. M., \& Pilling, S. (2015). Experience of care for mental health problems in the antenatal or postnatal period for women in the UK: a systematic review and meta-synthesis of qualitative research. Archives of women's mental health, 18, 745759. doi:10.1007\%2Fs00737-015-0548-6.

Park J., Solomon P., \& Mandell, D. (2006) Involvement in the child welfare system among mothers with serious mental illness. Psychiatric Services, 57, 493-7.

doi:10.1176/ps.2006.57.4.493.

Ramon, S., Castillo, H., \& Morant, N. (2001). Experiencing personality disorder: a participative research. International Journal of Social Psychiatry, 47(4), 1-15.

https://doi.org/10.1177/002076400104700401.

Royal College of Psychiatrists (2011) Parents as patients: Supporting the needs of patients who are parents and their children. College Report CR164. London: Royal College of Psychiatrists. Retrieved from https://www.rcpsych.ac.uk/docs/default-source/improving-care/better-mhpolicy/college-reports/college-report-cr164.pdf?sfvrsn=79416179_2.

Schofield, G., Moldestad, B., Hojer, I., Ward, E., Skilbred, D., Young, J., \& Havik, T. (2011). Managing Loss and a Threatened Identity: Experiences of Parents of Children Growing Up in Foster Care, the Perspectives of their Social Workers and Implications for Practice. British Journal of Social Work, 41.1, 74-92. https://doi.org/10.1093/bjsw/bcq073.

Social Care Institute for Excellence (2012). Think child, think parent, think family: final evaluation report. Retrieved from http://www.scie.org.uk/publications/reports/report56.pdf

Sheppard, M. \& Kelly, N. (2001) Social Work Practice with Depressed Mothers in Child and Family Care. The Stationery Office, London.

Stein, A., Pearson, R.M., Goodman, S.H., Rapa, E., Rahman, A., McCallum, M.,...Pariante, C. Effects of perinatal mental disorders on the fetus and child. The Lancet. 2014 Nov 15; 384(9956):1800-19. doi: https://doi.org/10.1016/S0140-6736(14)61277-0.

Turney, D. (2012) A relationship-based approach to engaging involuntary clients: the contribution of recognition theory. Child \& Family Social Work. 17, 149-159. https://doi.org/10.1111/j.1365-2206.2012.00830.x.

Westad, C. \& McConnell, D. (2011) Child Welfare Involvement of Mothers with Mental Health Issues, Community Mental Health Journal, 48(1), 29-37. http://dx.doi.org/10.1007/s10597-0119374-0. 
Table 1. Characteristics of participating women (including women in the wider study ( $\mathrm{n}=52$ ) who accessed support for a perinatal mental health difficulty and women in the current analysis $(\mathrm{n}=18)$ who were sampled from the wider study because they described social services involvement)

\begin{tabular}{|c|c|c|c|c|}
\hline & & \\
\hline & & $\mathbf{A}$ & $\begin{array}{l}\text { B (HSSI } \\
\text { mothers) }\end{array}$ & $\begin{array}{l}\text { C (LSSI } \\
\text { mothers) }\end{array}$ \\
\hline Characteristics & Category & $\begin{array}{l}\text { Full sample } \\
\text { from wider } \\
\text { study } \\
n=52\end{array}$ & $\begin{array}{l}\text { E.g. child } \\
\text { protection plan, } \\
\text { parenting } \\
\text { assessment, or } \\
\text { loss of custody } \\
\text { n=11 }\end{array}$ & $\begin{array}{l}\text { Other (lesser) } \\
\text { social services } \\
\text { involvement } \\
n=7\end{array}$ \\
\hline \multirow{5}{*}{ Age } & Mean age & 32 years & 28 years & 30 years \\
\hline & $\leq 25$ years & 11 & $7(39 \%)$ & 2 \\
\hline & $26-29$ years & 7 & $0(0 \%)$ & 2 \\
\hline & $30-39$ & 29 & 4 & 2 \\
\hline & $40+$ & 5 & 0 & 1 \\
\hline \multirow[t]{8}{*}{ Ethnicity } & White British & 28 & 6 & 6 \\
\hline & White Other & 6 & 1 & 0 \\
\hline & Black Caribbean & 5 & 3 & 1 \\
\hline & Black African & 4 & 1 & 0 \\
\hline & Black other & 2 & 0 & 0 \\
\hline & Asian & 4 & 0 & 0 \\
\hline & Arab & 1 & 0 & 0 \\
\hline & Mixed Race & 2 & 0 & 0 \\
\hline \multirow[t]{4}{*}{ Primary diagnosis* } & Depression & 19 & 2 & 2 \\
\hline & Anxiety & 9 & 0 & 1 \\
\hline & Personality disorder & 11 & 9 & 0 \\
\hline & Bipolar disorder/psychosis/schizophrenia & 13 & 0 & 4 \\
\hline \multirow[t]{4}{*}{ Level of education } & No formal qualifications & 8 & 3 & 1 \\
\hline & Secondary education & 22 & 7 & 4 \\
\hline & Undergraduate & 10 & 1 & 0 \\
\hline & Postgraduate & 12 & 0 & 2 \\
\hline \multirow[t]{3}{*}{ Housing tenure } & Owner occupied & 15 & 0 & 1 \\
\hline & Shared ownership & 1 & 0 & 0 \\
\hline & Private rental & 13 & 1 & 2 \\
\hline
\end{tabular}




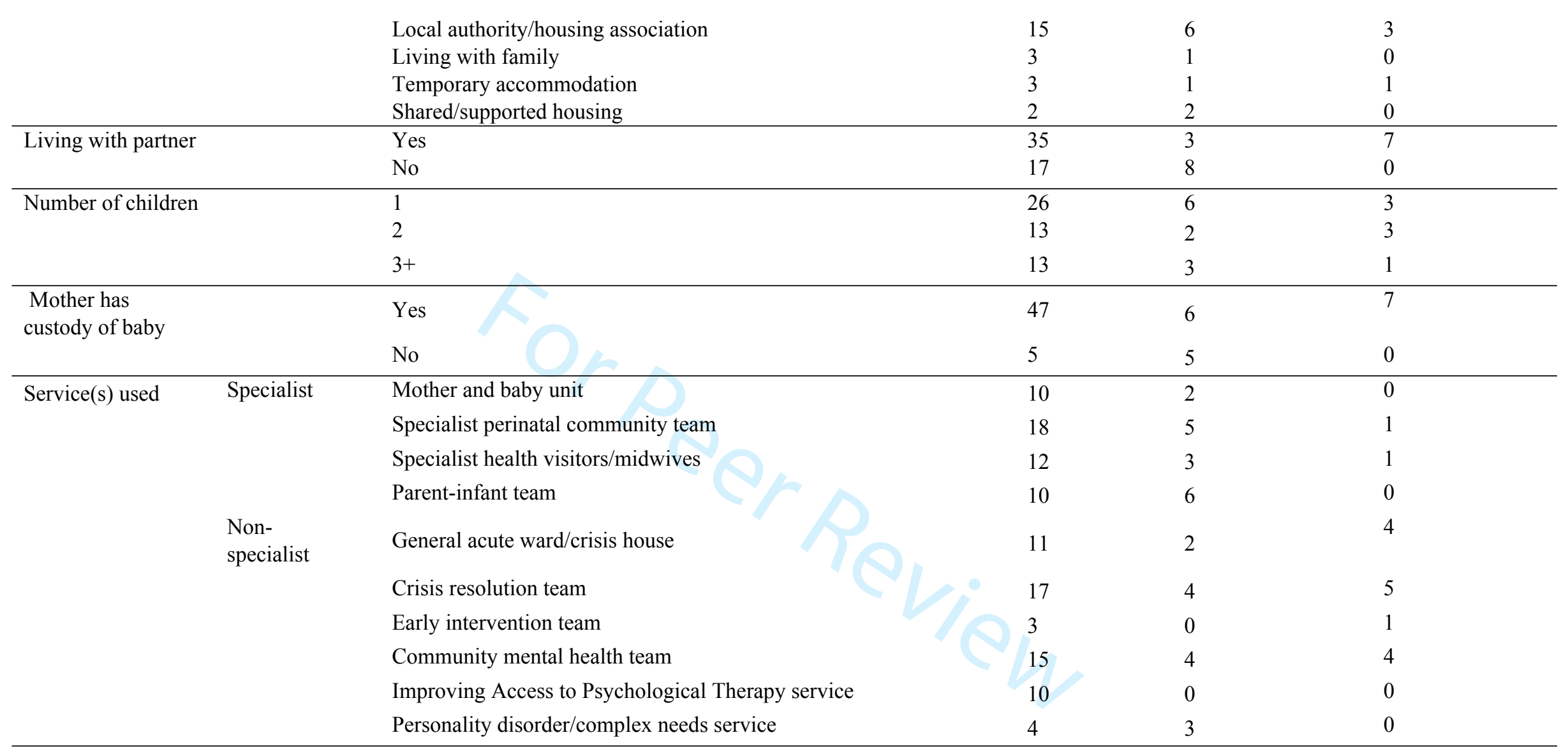


Table 2. Key themes and sub-themes identified

\begin{tabular}{|l|l|}
\hline Themes & Sub-themes \\
\hline Labelled as 'bad mothers' & Denied a fresh start \\
\hline & Misunderstanding mental health \\
\hline Set up to fail & Double bind \\
\hline & Not addressing mothers' own support needs \\
\hline & Increasing the strain on families \\
\hline & Powerlessness \\
\hline Turning points & A fresh perspective \\
\hline & A change in perspective \\
\hline
\end{tabular}

